\title{
A BUSCA DO EU A PARTIR DO OUTRO: CONSIDERAÇÕES ACERCA DA IDENTIDADE AFRICANA NO CONTO AS MÃOS DOS PRETOS DE BERNARDO HONWANA
}

\author{
THE SEARCH FOR THE INNER SELF FROM THE OTHER: \\ CONSIDERATIONS ABOUT AFRICAN IDENTITY ON THE SHORT \\ STORY AS MÃOS DOS PRETOS BY BERNARDO HONWANA
}

\author{
Celiomar Porfírio Ramos \\ Mestre em Estudos de Linguagem pela UFMT \\ Doutorando em Estudos Literários pela UNEMAT \\ E-mail: celiomarramoss@gmail.com
}

Marly Augusta Lopes de Magalhães Doutora em Ciências Linguísticas pela Universidad Central “Marta Abreu” de Las Villas Professor na UFMT

E-mail: professoramarlyaugusta@gmail.com

Resumo: O objetivo deste artigo é tecer algumas considerações acerca do conto As mãos dos pretos (2000), de Bernardo Honwana, a fim discutir e compreender a busca da identidade negra, a partir do personagem protagonista. A análise tem como ponto de partida o questionamento que impulsiona o conto, que é entender o motivo pelo de as palmas das mãos dos pretos terem uma cor diferente das demais partes do corpo. A fim de sustentar teoricamente o trabalho temos como base o texto de crítica literária de Antonio Candido Literatura e Sociedade (2006) e de outros teóricos e críticos que seguem a mesma linha de raciocínio.

Palavras-chave: Identidade Africana; Hibridismo; Conto Africano.

\begin{abstract}
The purpose of this article is making some considerations about the story "As mãos dos pretos", by Bernardo Honwana, in order to decode the focus which is the search for the black identity. The start point of the analysis is the questioning that drives the story once the main character aims to understand why the color of black people's hand are different from the remaining parts of his body asking some characters from his day to day. We establish the relation between the historical-social context and the literary text considering that the context exerts influence in the literary production.
\end{abstract}

Keywords: African identity; Hybridism; African Story.

\section{Introdução}

O texto literário tem como uma de suas principais características o fato de revelar sem se mostrar completamente. Isso graças a plurissignificação que ele carrega consigo. Segundo Trindade \& Gubert (2008, p. 15), a obra literária não é presa somente ao tempo em que o autor a escreveu. Ela tem como característica o fato de se encaixar no presente do leitor, que está procurando na narrativa, sua própria identidade. Sendo assim, é possível afirmar que a significação última do texto é inalcançável, ele sempre terá algo mais a revelar, a cada leitura.

Ao nos depararmos com o conto As mãos dos pretos (2000), de Luís Bernardo Honwana propomos realizar uma leitura que visa discutir sobre busca da identidade 
moçambicana. Aqui restringimos a Moçambique, pelo fato de acreditar que quando nos referimos a África, não devemos pensar numa única África, mas em Áfricas, pois estamos tratando de um continente, logo, os diferentes países que o compõem têm características particulares que os constituem.

No conto em questão não há uma demarcação precisa do contexto histórico, porém, é possível compreender a partir da análise textual, que se trata do período pós-colonial, ou seja, após a libertação do jugo do colonizador, Portugal.

O processo de colonização, segundo Fanon (1979), tem como característica a exploração do colonizado e, também, sua desfiguração, impondo ora de maneira consensual ora de forma violenta, a cultura do colonizador ao colonizado, "ao colonialismo não basta encerrar o povo em suas malhas, esvaziar seu cérebro de toda forma e todo conteúdo. Por uma espécie de perversão lógica, ele se orienta para o passado do povo oprimido, deforma-o, desfigura-o, aniquila-o" (FANON, 1979, p. 15).

Antes de partimos para a análise do conto é preciso compreender alguns aspectos teóricos acerca de literatura, sociedade, identidade, cultura e hibridização. Para isso, lançaremos mãos de alguns críticos literários e teóricos que sustentarão a análise, dentre eles Candido (2006), Abdala Junior (2007/1989), Hall (2003), Fanon (1979) e outros autores pertinentes à análise.

Em certa medida os aspectos supracitados - sociedade, identidade, cultura e hibridização - estão interligados. Tal afirmação baseia-se no fato de que "a literatura é também um produto social, exprimindo condições de cada civilização" (CANDIDO, 2006, p. 23). Abdala Junior (1989, p. 23), afirma que ninguém cria do nada, para que uma produção literária seja materializada, o escritor absorve substratos da sociedade e os metamorfoseia em sua escrita. Partindo desse princípio, podemos afirmar que, entre outros elementos, o escritor produz tendo como base sua realidade social. Vale mencionar que o escritor não realiza um retrato da sociedade, ele cria tendo como base a realidade, mas ao escrever há uma reestruturação. Além disso, Abdala Junior (1989) afirma ainda que, muitas vezes, o escritor acredita que sua produção é apenas sua, não tendo consciência que a sociedade se escreve e inscreve por meio dele.

No que diz respeito à identidade, entendemos que é uma discussão complexa e, muitas vezes, pouco compreendida. Porém, algo é certo, segundo Hall, todas as identidades culturais estão fragmentadas, descentradas, consequentemente, não há uma identidade una, pura, "as nações modernas são todas híbridos culturais" (HALL, 2005, p. 62). 
Considerando as noções modernas acerca da identidade, que compreende que não há uma identidade una, que todas são híbridas, somos levados a crer que atualmente é impossível pensar em uma identidade completa, unificada, pois a sociedade atual é constituída por identidades múltiplas, variável que são alteradas constantemente.

Apesar disso, observamos que a sociedade busca incessantemente uma identidade, ou seja, procura traços comuns que a identifique ou que a diferencie das outras. Dado o exposto, realizaremos uma leitura analítica do conto As mãos dos pretos, observando a busca da identidade, por meio do questionamento levantando ao longo do enredo pelo protagonista.

Acreditamos que indagação em vários segmentos da sociedade, sem êxito, do personagem protagonista do conto, sobre o motivo da cor das mãos dos pretos ser diferente das demais partes do corpo, traz implícita a busca de uma identidade.

Ao tratar sobre identidade não há como deixar de adentrar em uma discussão sobre cultura, pois elas estão interligadas. Se a identidade não é fixa, o sujeito assume identidades diferentes em distintos momentos, logo, pode-se compreender que a cultura não é "pura", assim como a identidade, ela é influenciada por outras. Tal argumento nos leva a seguinte assertiva: se uma cultura é influenciada por outra(s) ela pode ser denominada de cultura hibrida.

O processo de hibridização influência de maneira significativa, no que diz respeito à identidade, a fim de reestruturá-la, pois conforme Bhabha (1998) ao tratar sobre a cultura hoje, em virtude da hibridização, estamos em constante reestruturação da identidade e, por isso, vivendo no "além":

O "além" não é nem um novo horizonte, nem o abandono do passado... [...] encontramo-nos no momento de trânsito em que espaço e tempo se cruzam para produzir figuras complexas de diferentes identidades, passado e presente, interior e exterior, inclusão e exclusão. Isso porque há uma sensação de desorientação, um distúrbio de direção, no "além": um movimento exploratório incessante [...] (BHABHA, 1998, p. 19).

Seguindo a linha de pensamento de Bhabha (1998), a nossa reflexão é a de que a identidade e a cultura de um povo não é algo estanque, mas está num processo de constante reestruturação e/ou negociação, ora de maneira consensual ora de maneira conflituosa.

Canclini (2013) compreende que, atualmente, nenhuma cultura está livre de influenciar e ser influenciada e, por isso, considera todas híbridas. Ao afirmar que uma cultura é híbrida, não a entendemos como uma cultura misturada com outra(s), mas trata-se de "processos socioculturais nos quais estruturas ou práticas discretas que existem de forma 
separada, se combinam para gerar novas estruturas, objetos e práticas" (CANCLINI, 2013, p. 09).

Vimos que a busca pela identidade é perpassada por diferentes aspectos - identidade, cultura e hibridização. Essa busca nos faz perceber que se trata de uma procura incessante, pois não se satisfaz ao encontrar certas respostas. Sendo assim, não é possível ter acesso a uma identidade ou a cultura "pura", pelo fato de todas serem híbridas. Entretanto, apesar de ser uma tentativa fadada ao fracasso, dada a constante reestruturação da identidade, essa busca não cessa, é constante. Isso é possível observar no conto em análise.

\section{A busca do eu a partir do outro - análise do conto "As mãos dos pretos"}

A partir da leitura analítica do conto As mãos dos pretos, inferimos que a principal meta do protagonista é a busca pela identidade, isso de dá pelo fato dele ter sido instigado a procurar a resposta para um questionamento e, ao mesmo tempo, não se satisfazer com as respostas dadas e, desta forma, investigar, sempre, uma nova visão acerca do assunto nas diferentes camadas sociais. O processo investigativo que move o conto tem a finalidade de compreender qual o verdadeiro motivo das mãos dos pretos ser de uma cor distinta das demais partes do corpo.

Torna-se relevante registrar que o questionamento é feito em diferentes camadas sociais, sendo: Senhor Professor, Senhor Padre, Dona Dores, Senhor Antunes Coca-Cola, Senhor Frias, o livro, Dona Estefânia e, também, a mãe do personagem. Assim, pode-se notar que parte de uma visão macro, o professor, para uma visão micro, a mãe. Essa estruturação não acontece de maneira abrupta, ao contrário, é gradativo.

Ao abordar sobre identidade temos consciência que não se pode considerá-la como algo singular, ao contrário, devemos pensar sobre identidades, tendo como base a afirmação de Stuart Hall (2005) acerca do tema, ao defender que não possuímos apenas uma identidade, mas várias, conforme o contexto histórico que estamos inseridos. Outro fator relevante sobre o termo "identidades", em especial, africanas é a consciência de que não lidamos com uma África com uma única cultura, mas um continente - o Africano - constituído por várias Áfricas, ou seja, por povos diferentes, com culturas diversas e dialetos distintos.

Partiremos, agora, para a análise das diferentes perspectivas apresentadas pelos personagens acerca do questionamento levantado pelo protagonista do conto. O primeiro, o professor, que é o responsável por levantar o questionamento sobre as mãos dos pretos. Sua fala nos leva a refletir para o fato de que, por muito tempo e, ainda hoje, o negro é considerado 
como um ser inferior; fatores históricos, dentre eles a escravidão corrobora para a diminuição dos negros, colocando-os em uma condição de subjugados aos ditos brancos. A visão do professor é narrada pelo personagem protagonista:

\begin{abstract}
Já não sei a que propósito é que isto vinha, mas o senhor Professor disse um dia que as palmas das mãos dos pretos são mais claras do que o resto do corpo porque ainda há poucos séculos os avós dele andavam com elas apoiadas ao chão, como bichos do mato sem as exporem ao sol, que lhes ia escurecendo o corpo [...] (HONWANA, 2000, p. 25).
\end{abstract}

Esse fragmento do conto traz à tona pontos extremamente relevantes acerca da visão que se tem do negro. Esses eram equiparados e, em algumas ocasiões, tratados como animais irracionais. A explicação um tanto pretensiosa dada pelo professor colocando o negro como um animal irracional que foi domesticado para servir ao homem ${ }^{1}$.

Considerando o exposto, podemos verificar que a primeira percepção que se tem com a versão do professor é que ele não apresenta, necessariamente, os negros como seres humanos, mas como animais irracionais.

O padre representando a ordem religiosa coloca os pretos sem prestígio algum, como a parte mais sem valor da sociedade, ao afirmar que "até os pretos eram melhor que nós [...]".A ideia do professor foi lembrada após a fala do padre, ou seja, há um fluxo de consciência: “[...] lembrei-me disso quando o Senhor padre, depois de dizer na catequese que nós não prestávamos mesmo para nada e que até os pretos eram melhores que nós [...]" (HONWANA, 2000, p 25).

Notamos que o professor compreende os pretos como bichos do mato. Por outro fator, o padre os vê como uma parte sem valor da sociedade. O que se percebe, em ambas condutas, é que a identidade atribuída ao preto é permeada por uma imagem de um ser sem valor. Isso se deve ao imaginário instaurado na África pós-colonização, tanto o professor quanto o padre são, com base na leitura realizada, frutos de um representante maior, do colonizador. Apesar de o professor ter raízes africanas, conforme afirma o conto, - "os avôs dele" - é possível observar que ele já não se sente preto, por estar sob o domínio de outra cultura, a do colonizador.

O padre apresenta a seguinte justificativa pelas mãos dos pretos serem mais claras: “[...] voltou a falar nisso de as mãos serem mais claras, dizendo que isso era assim porque eles andavam com elas escondidas, andavam sempre de mãos postas, a rezar" (HONWANA, 2000, p. 26).

\footnotetext{
${ }^{1} \mathrm{O}$ termo "homem" aqui é entendido como o homem branco, uma vez que o negro é compreendido como animal irracional.
} 
Vale lembrar, ainda, que a cultura religiosa imposta pelo colonizador - o catolicismo - o ato de rezar é compreendido, dentre as muitas finalidades, como uma forma de buscar, da purificação. $\mathrm{O}$ fato de os pretos estarem sempre a rezar indica a necessidade de purificação e as palmas das mãos com a cor diferente pode ser vista como uma dádiva ao negro.

É pertinente ressaltar que isso representa um processo de evolução para os pretos que, em decorrência da reza, ou seja, do contato com o divino aqui representado pelo padre, que consequentemente, personifica o colonizador, neste contexto, deixam de ser completamente irracionais, como sugere o professor e passam a ter algum valor, pois até então era impossível percebê-los com algum valor.

Por oportuno, a análise baseia-se na busca da identidade, procurando entender o motivo pelo qual as palmas das mãos dos pretos serem mais claras. Essa busca da identidade fica evidente no seguinte fragmento: “[...] eu achei um piadão tal essa coisa de as mãos dos pretos serem mais claras que agora é ver-me não largar seja quem for enquanto não me disser por que é que eles têm as mãos assim tão claras" (HONWANA, 2000, p. 26).

A identidade dos pretos, neste contexto, está perpassada pela do colonizador, ou seja, tornou-se híbrida. Segundo Hall, essa crise é uma das características da sociedade globalizada, pois "as velhas identidades, que por tanto tempo estabilizaram o mundo social, estão em declínio fazendo surgir novas identidades e fragmentando o indivíduo moderno, até aqui visto como um sujeito unificado" (HALL, 1992, p. 2).

Assim, o preto passa a ter consciência da diferença de cor e a questiona, apenas após ter contato com o branco, ou seja, após imporem que eles eram pretos, afirma Munanga: "Os pretos não foram colonizados porque são negros, ao contrário, na tomada de sua terra e na expropriação de sua força de trabalho com vista a expansão colonial, é que os negros tornaramse pretos" (MUNANGA, 1985, p. 79 apud ABDALA JUNIOR, 1989, p. 19).

Dentro destes contornos partimos para a próxima resposta, a de Dona Dores:

A Dona Dores, por exemplo, disse-me que Deus fez-lhes as mãos assim mais claras para não sujarem a comida que fazem para os seus patrões ou qualquer outra coisa que lhes mande fazer e que não deve ficar senão limpa (HONWANA, 2000, p. 26).

Mas, a bem da verdade, o que ora se busca enfatizar é que a ideia presente de preto subjugado ao branco, de colonizado submisso ao colonizador é entendida como uma ordem divina “Deus fez-lhes as mãos assim [...]”. Logo, está destinado ao preto servir ao seu senhor, em razão de ele ter sido criado, segundo a resposta de Dona Dores para servir.

Além do fato de os negros serem subjugados, há um elemento mencionado no fragmento do conto que merece destaque: os pretos são vistos como seres sujos, conforme é 
possível verificar no fragmento acima citado. Nota-se que a ideia do branco opor-se ao preto se equipara à diferença entre o limpo (branco) e o sujo (preto). Além disso, mais uma vez é evocado o imaginário de preto criado para servir. O enredo apresenta África sob a perspectiva do colonizador e procura reafirmar e plantar no imaginário dos pretos/africanos que eles foram criados para servir.

$\mathrm{Na}$ busca de elucidar o questionamento, o próximo personagem apresentado é conhecido como Antunes Coca-Cola, representando, por meio do nome "Coca-Cola" o imperialismo, a exploração do povo preto, pois é afirmado no conto que o Senhor Antunes "aparece na vila de vez em quando, quando as "coca-colas" das cantinas já tenham sido vendidas [...]" (HONWANA, 2000, p 27). Antunes Coca-Cola representa o colonizador, a modernidade chegando e se instaurando na colônia, no que é símbolo do atrasado.

No escopo maior, cada personagem apresentado mantém certa relação e tem conhecimento da versão que antecede a suas considerações acerca da resposta sobre o motivo pelo qual as mãos dos pretos serem mais claras que o resto do corpo e, assim, procura desconstruir as respostas, apresentando uma nova que sobreponha à versão anterior.

Essa percepção nos remete ao fato de que a identidade não é algo estático, mas extremamente dinâmica, pois está em constante modificação e, dessa forma, justifica-se a percepção das pessoas envolvidas na história.

Antunes Coca-cola apresenta a seguinte versão para justificar as mãos dos pretos foi:

Antigamente, há muitos anos, Deus, Nosso Senhor Jesus Cristo, Virgem Maria, São Pedro, muitos outros santos, todos os anjos que nessa altura estavam no céu e algumas pessoas que tinham morrido e ido para o céu, fizeram uma reunião e resolveram fazer pretos. Sabes como? Pegaram em barro, enfiaram-no em moldes usados para cozer o barro das criaturas, levaram-nas para os fornos celestes; como tinham pressa e não houvesse lugar nenhum ao pé do brasido, penduraram-nas nas chaminés. Fumo, fumo, fumo e aí os tens escurinhos como carvões. E tu agora queres saber por que é que as mãos deles ficaram brancas? Pois então se eles tiveram de se agarrar enquanto o barro deles cozia?! (HONWANA, 2000, p. 27).

O termo "Deus" é citado mais uma vez. Todos os personagens apresentados até o momento o citaram. Com base na análise concluímos que há uma percepção de que Deus compactua com o fato de o preto ser subjugado ao branco. Ou seja, que a submissão dos pretos e a superioridade do branco acontecem pela vontade de Deus.

À luz de tais considerações, faz-se necessário reportar alguns fatos históricos. Quando Portugal colonizou parte da África - aqui nos restringimos aos países africanos de língua portuguesa - consequentemente, sobrepõe sua cultura a dos africanos, dentre as imposições podemos citar a língua e a religião. Abdala Junior (1989, p. 18) ao tratar sobre o tema acima 
afirma que "o processo de aculturação do colonialismo português visava à desculturação dos outros povos". A religião, neste contexto, recebe atenção especial, pois visa persuadir o povo africano de que eles são inferiores ao colonizador.

O conto é marcado pela presença da religião católica, há marcas textuais que comprovam a afirmação, dentre elas podemos mencionar as palavras Deus, Jesus Cristo, Virgem Maria, São Pedro e outros santos. Considerando o fragmento acima, percebemos que a justificativa dada por Antunes Coca-Cola apresentou o processo de criação para esclarecer a dúvida do personagem protagonista do conto. De acordo com o conto, enquanto barro os pretos são iguais as outras criaturas, ou seja, aos brancos. O que corrobora para essa percepção é o fato de o barro ter sido colocado nos "moldes usados para cozer o barro das criaturas". No entanto, quando os pretos foram levados para o processo de cozimento não havia lugar junto as demais criaturas, dessa forma "como tinha pressa e não houvesse lugar ao pé do brasido, penduraram-nas na chaminés".

Isso implica que desde a criação os pretos não podem estar entre os brancos, pois não os caberiam, mas decidiram criá-los, por haver necessidade de criatura para servi-los como, enquanto seres superiores. A chaminé apesar de estar situada em um ponto alto de certas residências e, também, anunciar todas as manhãs o novo despertar, embora tenha essas utilidades, não é vista com bons olhos, por ser o local pelo qual sai às impurezas após a queima do carvão. E, assim, estando os pretos, em processos de transformação, enquanto barro, e estando pendurados nela, se tornam, para muitos, sinônimo de impureza e, consequentemente, inferiores as criaturas cozidas ao pé do brasido.

Em seguida a exegese apresentada por Antunes Coca-Cola sobre as mãos dos pretos é que esses tinham um contato mais próximo à chaminé, ou seja, ficaram pendurados a ela. Tal fato reflete que, desde muito cedo, antes mesmo de ser cozido, ou seja, de se tornar seres, há um o embate social entre brancos e pretos, de que estes devem estar sempre a serviço do outro.

Posteriormente, o Senhor Frias que havia ouvido a versão de Antunes Coca-cola afirma que tudo o que foi narrado anteriormente, não passava de devaneios: "Chamou-me, depois de o Senhor Antunes se ter ido embora, e disse-me que tudo que eu tinha estado ali a ouvir de boca aberta era uma grandessíssima peta" (HONWANA, 2000, p. 27). Convém pontuar o que já se havia percebido sobre a identidade, que ela é efêmera, pois quando acreditamos que foi encontrada uma justificativa para as mãos dos pretos, aparece uma nova versão, proporcionando, assim, a constituição de uma nova identidade que estará passível de ser reconstruída.

A versão apresentada pelo Senhor Frias era: 
Coisa certa e certinha sobre isso das mãos dos pretos era o que ele sabia: que Deus acabava de fazer os homens e mandava-os tomar banho num lago do céu. Depois do banho as pessoas estavam branquinhas. Os pretos, como foram feitos de madrugada e a essa hora a água do lago estivesse muito fria, só tinham molhado as palmas das mãos e as plantas dos pés, antes de se vestirem e virem para o mundo (HONWANA, 2000, p. 27)

De acordo com a versão do conto, a nova ordem celeste é marcada pelo poder do dominador, ou seja, a primazia dos brancos sobre os pretos. A presença da igreja valida o lugar do preto, considerando o fato de que, mais uma vez, é mencionado Deus e a criação do homem. No fragmento acima somos informados de que os homens eram criados e mandados para o banho, após o contato com a água as pessoas tornavam-se brancas.

$\mathrm{O}$ fato de os homens terem sido criados/feitos no decorrer do dia e os pretos durante a madrugada deixa subentendido que há um destino traçado. Assim, a ordem que os homens e os pretos foram criados merece atenção, pois em tudo há prioridade hierárquica, primeiramente, criar o homem/branco e, logo após, os pretos. No decorrer dos fatos, observamos, ainda, que o termo homem é substituído por “pessoas branquinhas", enquanto isso, para o preto era, apenas, o preto, pois não há outra designação para conceituá-lo.

$\mathrm{Na}$ condição de regente dos questionamentos a criança que busca compreender a identidade do negro, não se convence com os argumentos do Senhor Frias e parte em na busca de uma nova definição. A resposta que agora foi encontrada está em um livro que afirma: "Mas eu li num livro, que por acaso falava nisso, que os pretos têm as mãos assim mais claras por viverem encurvados, sempre a apanhar o algodão branco de Virgínia e de mais não sei onde" (HONWANA, 2000, p. 27).

Observando tal perspectiva apresentada pelo livro para justificar o motivo das mãos dos pretos serem mais clara vimos que se dá em virtude de eles apanharem algodão branco.

Há fatores que retratam uma postura que não se sustenta do ponto de vista lógico, de que, os pretos viviam encurvados devido às práticas do trabalho. $\mathrm{O}$ desfecho não pode ser outro, ao analisarmos esse fragmento de que os pretos se curvam perante os brancos, pode-se inferir aqui personificação do branco por meio do algodão. Outro fator que colabora para tal visão é que o preto sempre estará curvado, ou seja, subjugado ao branco mesmo que para isso seja necessário o uso da força.

O verbo "apanhar" é um dos elementos textuais que nos leva a essa compreensão. Apesar de ele estar empregado como sinônimo de "pegar", o vocábulo em questão pode ser compreendido, segundo o dicionário Online de Português ${ }^{2}$ como levar uma surra. Entendemos

\footnotetext{
${ }^{2}$ Disponível em: https://www.dicio.com.br/apanhar/. Acesso em 20 de agosto de 2018.
} 
que os pretos têm as mãos assim como sinal que eles devem permanecer subjugados, encurvados a servir os brancos. A explicação encontrada no livro não foi suficiente para convencer a criança em sua busca.

A versão apresentada pelo livro não convenceu a Dona Estefânia e ela apresenta uma nova justificativa: "Já se vê que a Dona Estefânia não concordou quando eu the disse isso. Para ela é só por as mãos desbotarem à força de tão lavadas". Tal afirmativa denota que a mão do negro só ficou mais clara que as demais partes do corpo graças à força das tão lavada que representa a cultura imposta pelo outro, o branco. A lavada foi possível, graças ao colonizador que chegou, caso contrário, não haveria o processo de "lavagem", ou seja, a hibridização das culturas e, também, a consciência da diferença entre eles - colonizador versus colonizado, brancos versus negro.

No entanto, não é o que se verifica nos argumentos apresentados posteriormente pela a mãe da criança. Muitas respostas foram apresentadas no decorrer do conto e, nesse passo, deverão ser interpretadas à luz de princípios que não venham colidir com os principais pilares argumentativos. É apresentada a última versão do conto sobre as mãos dos pretos. Agora é a mãe da criança que, ao ver a procura incessante de respostas que move o enredo do conto, diante das expectativas da criança, decide se manifestar como a fonte primordial.

A resposta da mãe sobre o questionamento da criança foi:

\begin{abstract}
Deus fez os pretos porque os tinha de haver. Tinha de os haver, meu filho, Ele pensou que realmente tinha de o haver... Depois arrependeu-se de os ter feito porque os outros homens se riam deles e levavam-nos para as casas deles para os pôr a servir como escravos ou pouco mais. Mas como Ele já os não pudesse fazer ficar todos brancos porque os que já se tinham habituado a vê-los pretos reclamariam, fez com que as palmas das mãos deles ficassem exatamente como as palmas das mãos dos outros homens. E sabes porque é que foi? Claro que não sabes e não admira porque muitos e muitos não sabem. Pois olha: foi para mostrar que o que os homens fazem é apenas obra dos homens. Deve ter sido a pensar assim que ele fez com que as mãos dos pretos fossem iguais às mãos dos homens que dão graças a Deus por não serem pretos (HONWANA, 2000, p. 28).
\end{abstract}

É possível observar o silenciamento do negro, pois por a mãe ser "mulher + preta" ela não tem direito a voz, antes dos humanos, ou seja, antes do branco.

Vimos que, em certa medida, há uma sintonia no fato do preto não ter voz e ser subjugado ao branco com o enredo do conto, pois os que foram questionados acerca do assunto eram, segundo a leitura realizada, brancos ou apesar de pretos sentiam-se brancos representando, assim, o colonizador.

Nota-se que o sofrimento por desconhecer a identidade do preto proporciona um enorme desconforto à criança que, por isso, sai em busca de respostas. A falta de uma resposta 
convincente não é um motivo, até então, para desmotivar essa busca. Isso fica evidente no seguinte fragmento do conto:

Bem, eu não sei o que vá pensar disso tudo, mas a verdade é que ainda que calosas e gretadas, as mãos dum preto são sempre mais claras do que todo o resto dele.

[...] eu não me cansava de insistir sobre a coisa [...] (HONWANA, 2000, p. 28).

A criança apresenta uma constante busca compreender sua identidade, por meio de questionar as pessoas que estão em sua volta. É possível entender, ainda que ela se encontra perdida, pelo fato de haver uma constante (des)construção da identidade.

Dado o exposto, sempre, é necessário lutar para a construção de uma nova identidade, apesar de haver uma crise de identidade, em virtude da hibridização. Essa procura, segundo Hall (1995, p. 2) é “[...] uma 'celebração móvel': formada transformada continuamente em relação às formas pelas quais somos representados ou interpelados nos sistemas culturais que nos rodeiam".

Mais uma vez, no conto, é mencionado o nome de Deus, agora, na resposta da mãe. Segundo Cardoso (s/d, p. 10), a figura Deus é apresentada no conto de maneira explicita três vezes e de maneira implícita em mais de uma das explicações, logo, observa-se que a metade das respostas dadas têm caráter religioso, todavia, das respostas supracitadas verifica-se que não foi eliminado o preconceito para com os pretos. Segundo a afirmativa da mãe, o Criador fez o preto porque ele tinha que existir por diversos motivos.

Na versão da mãe, Deus arrepende-se de criar o preto, não por ele ter uma cor diferente, mas em virtude do branco. Somos levados a entender que o preto, ao contrário do que foi apresentado até agora, não foi criado para servir o branco, pois a mãe equipara os pretos aos brancos, quando os chamam de homens. Isso é verificável em: "os outros homens". Entretanto, posteriormente, percebemos que apesar de ela os equiparar é como se o preto fosse "uma espécie de portugueses de segunda classe" (ABDALA JUNIOR, 1989, p. 68).

Notamos que a mãe elenca alguns elementos presentes na vida dos pretos, dentre eles a exploração da miséria, a exclusão e da fragmentação da (des)humanidade, ou seja, aspectos que contribuem na constituição da identidade do negro e, também, para os conflitos da identidade. Essa nova realidade emerge, exclusivamente, das relações sociais, como é possível observar em: "riram deles e os levavam-nos para casa deles para por a servir de escravos [...]".

A escravidão é mencionada pela mãe em sua resposta. Além disso, é possível observar um processo de "adestramento" do preto, quando eles eram levados para as casas, aqui entendemos como os países, dos brancos para serem explorados. 
$\mathrm{Na}$ resposta da mãe ao protagonista, ela menciona que Deus ao se arrepender de ter criado os negros, cogita torná-los brancos, porém teme a reclamação dos brancos:

\begin{abstract}
Mas como Ele já os não pudesse fazer ficar todos brancos porque os que já se tinham habituado a vê-los pretos reclamariam, fez com que as palmas das mãos deles ficassem exatamente como as palmas das mãos dos outros homens. E sabes porque é que foi? Claro que não sabes e não admira porque muitos e muitos não sabem (HONWANA, 2000, p. 28).
\end{abstract}

É, sem dúvidas, um tanto intrigante observar o poder que o branco possui. Tamanha é a soberania dele, que até o Criador, Deus, no conto, teme a repreensão do homem branco.

Para que isso não ocorresse, Deus fez com que as palmas das mãos dos pretos ficassem iguais as mãos dos outros homens. Podemos notar aqui, o confronto de duas concepções humanas, no sentido da negação da alteridade e a submissão dos pretos perante o colonizador. A mãe acrescenta em sua resposta que tudo isso tem um objetivo:

[...] Pois olha: foi para mostrar que o que os homens fazem é apenas obra dos homens. Deve ter sido a pensar assim que ele fez com que as mãos dos pretos fossem iguais às mãos dos homens que dão graças a Deus por não serem pretos (HONWANA, 2000, p. 28).

A mãe desconstrói a ideia de que o Criador (Deus) influenciou no destino do preto e deixa claro que as atrocidades contra os pretos são frutos, apenas, das atitudes humanas, o que deixou de ser uma ideia, para tornar-se uma realidade no cotidiano dessas pessoas.

Apesar de apresentar um discurso de igualdade na versão da mãe, há marcas textuais que nos leva a crer que ela apenas quis dar uma versão que faça a criança negra acreditar que o branco e o negro são iguais, apesar de não acreditar nisso, pois ela difere as mãos - "mãos dos pretos" e "mãos dos homens" - como se os pretos fossem seres inferiores.

O vazio provocado pelas faltas de respostas convincentes, ao contrário do esperado, não trouxe angústia à criança, não provocou atordoamentos, mas apatia a determinadas questões. Daí surge a indiferença pelo excesso de possibilidades socializadoras. A apatia gera a aceleração das experimentações e explorações.

Para finalizar o conto a criança preta vai brincar, possibilitando ao leitor duas leituras, a primeira é a de que a resposta da mãe foi satisfatória e convincente, bem como a de todos os demais personagens do conto. Já a segunda possibilidade é a de que o personagem protagonista não se convenceu de nenhuma das respostas e, por isso, desistiu da procura incessante e decide, apenas, viver. A última possibilidade apresentada é a mais coerente, de acordo com a leitura realizada, pois a busca de uma resposta precisa e, consequentemente, da identidade pura e 
genuína é uma investigação fadada ao fracasso, uma vez que temos identidades, conforme afirma Stuart Hall.

A mãe ao tomar consciência que a criança, protagonista do conto, está refletindo sobre o seu lugar na sociedade, por meio do questionamento realizado, após apresentar a resposta tem uma crise de choro. Acredita-se que ela tem tal atitude por saber que por mais que pregue a igualdade, neste contexto, o negro sempre vai estar sob o jugo do branco, sempre estará subjugado.

\section{Referências}

ABDALA JUNIOR, Benjamin. Literatura: história e política - Literaturas de língua portuguesa no século xx. Editora Ática: São Paulo, 1989.

BHABHA, Homi. O local da cultura. Belo Horizonte: Editora UFMG, 1998.

CANCLINI, Nestor Garcia. Culturas Híbridas: Estratégias para entrar e sair da modernidade. 4 ed. 6 reimp. - São Paulo: Editora da Universidade de São Paulo, 2013.

CANDIDO, Antonio. Literatura e Sociedade. Rio de Janeiro: Outro sobre Azul, 2006.

CANO, Morales José Antônio. Deseño y Organización de Empresas. 2006

CARDOSO, Laís de Almeida. Literatura, Sociedade e Identidade Cultural: Um diálogo entre "As mãos dos pretos", de Luis Bernardo Honwana, "Por que o negro é preto", de Câmara Cascudo, e Macunaíma, de Mário de Andrade. Revista Crioula, nº 13, 2013. Disponível em: http://www.revistas.usp.br/crioula/article/view/64227/66916. Acesso em $13 \mathrm{de}$ janeiro de 2015.

FANON, Frantz. Os condenados da terra. 2. Ed. Rio de Janeiro: Civilização Brasileira, 1979.

FANON, Frantz. Pele negra, máscaras brancas. Tradução de Renato da Silveira . - Salvador: EDUFBA, 2008.

HALL, Stuart. A identidade cultural na pós-modernidade. $10^{\mathrm{a}}$ Ed. Rio de Janeiro: DP\&A, 2005.

HONWANA, Luís Bernardo, “As mãos dos pretos” in: Nós Matamos o Cão-Tinhoso. $5^{\mathrm{a}}$ ed. Lisboa: Afrontamento, 2000. 